ARTICLE

https://doi.org/10.1038/s41467-018-07937-w

\title{
Room-temperature electrochemical water-gas shift reaction for high purity hydrogen production
}

Xiaoju Cui ${ }^{1,2}$, Hai-Yan Su${ }^{3}$, Ruixue Chen ${ }^{1,2}$, Liang $\mathrm{Yu}^{1}$, Jinchao Dong ${ }^{2}$, Chao Ma (10 ${ }^{4}$, Suheng Wang ${ }^{1,2}$, Jianfeng Li (ib ${ }^{2}$, Fan Yang (1) ${ }^{1}$, Jianping Xiao ${ }^{1}$, Mengtao Zhang ${ }^{5}$, Ding Ma (i) ${ }^{5}$, Dehui Deng ${ }^{1,2}$, Dong H. Zhang (i) ${ }^{3}$, Zhongqun Tian (D) ${ }^{2} \&$ Xinhe Bao ${ }^{1}$

Traditional water-gas shift reaction provides one primary route for industrial production of clean-energy hydrogen. However, this process operates at high temperatures and pressures, and requires additional separation of $\mathrm{H}_{2}$ from products containing $\mathrm{CO}_{2}, \mathrm{CH}_{4}$ and residual $\mathrm{CO}$. Herein, we report a room-temperature electrochemical water-gas shift process for direct production of high purity hydrogen (over 99.99\%) with a faradaic efficiency of approximately $100 \%$. Through rational design of anode structure to facilitate CO diffusion and PtCu catalyst to optimize $\mathrm{CO}$ adsorption, the anodic onset potential is lowered to almost $\mathrm{O}$ volts versus the reversible hydrogen electrode at room temperature and atmospheric pressure. The optimized PtCu catalyst achieves a current density of $70.0 \mathrm{~mA} \mathrm{~cm}^{-2}$ at 0.6 volts which is over 12 times that of commercial Pt/C (40 wt.\%) catalyst, and remains stable for even more than $475 \mathrm{~h}$. This study opens a new and promising route of producing high purity hydrogen.

\footnotetext{
${ }^{1}$ State Key Laboratory of Catalysis, Collaborative Innovation Center of Chemistry for Energy Materials, Dalian Institute of Chemical Physics, Chinese Academy of Sciences, Dalian 116023, China. ${ }^{2}$ Collaborative Innovation Center of Chemistry for Energy Materials, College of Chemistry and Chemical Engineering, Xiamen University, Xiamen 361005, China. ${ }^{3}$ State Key Laboratory of Molecular Reaction Dynamics, Dalian Institute of Chemical Physics, Chinese Academy of Sciences, Dalian 116023, China. ${ }^{4}$ Center for High Resolution Electron Microscopy, College of Materials Science and Engineering, Hunan University, Changsha 410082, China. ${ }^{5}$ College of Chemistry and Molecular Engineering, Peking University, Beijing 100871, China. These authors contributed equally: Xiaoju Cui, Hai-Yan Su, Ruixue Chen. Correspondence and requests for materials should be addressed to D.D. (email: dhdeng@dicp.ac.cn)
} 
T he water-gas shift (WGS) reaction, i.e., $\mathrm{CO}+\mathrm{H}_{2} \mathrm{O} \rightarrow \mathrm{H}_{2}+$ $\mathrm{CO}_{2}$, is a key step in carbon-based energy processes for large-scale hydrogen production ${ }^{1-5}$. The process is typically operated at 1.0-6.0 MPa under high temperatures to overcome the sluggish reaction kinetics, though the reaction is mildly exothermic $\left(\sim 41 \mathrm{~kJ} \mathrm{~mol}^{-1}\right)^{6,7}$, and a lower temperature will favor the equilibrium moving toward hydrogen production ${ }^{8}$. As a compromise, industrial plants often use a two-step WGS reactor where the feed gas is firstly led through a high-temperature $\left(320-450{ }^{\circ} \mathrm{C}\right)$ reactor to initiate the reaction with high rate and then a lower temperature $\left(180-250^{\circ} \mathrm{C}\right)$ reactor to further improve $\mathrm{CO}$ conversion ${ }^{9-12}$. Apart from the harsh conditions, $\mathrm{H}_{2}$ produced by the WGS reaction contains $\mathrm{CO}$ residuals (around $1-10 \%$ ) and significant quantities of $\mathrm{CO}_{2}$ and $\mathrm{CH}_{4}$, etc., which needs extra processes of separation and purification (Fig. 1) so as not to affect the downstream applications ${ }^{13}$. As an example, a trace amount of $\mathrm{CO}$ (around $100 \mathrm{ppm}$ ) in $\mathrm{H}_{2}$ will seriously poison the Pt-based catalyst on the anode of proton exchange membrane fuel cell and reduce the performance significantly ${ }^{14}$. Therefore, the direct production of high purity hydrogen under mild conditions is more economical and eco-friendly but a challenging task, which requires innovative catalytic processes.

Electrochemically decoupling the WGS redox reaction to separated cathodic reduction reaction and anodic oxidation reaction in an electrolytic cell and using electric-potential as the driving force of the process is a promising approach of circumventing the aforementioned harsh conditions ${ }^{15,16}$. The catalyst and electrode structure significantly affect the intrinsic activity and micro-kinetics for the reaction, and thus need elaborate design towards higher reaction performance under milder conditions.

Herein, we report a room-temperature electrochemical water-gas shift (EWGS) process, where the water is reduced to $\mathrm{H}_{2}$ at the cathode and the $\mathrm{CO}$ is oxidized at the anode. Through rationally designing the anode structure and catalyst to promote the $\mathrm{CO}$ oxidation reaction, the anodic onset potential can be lowered to almost $0 \mathrm{~V}$ versus the reversible hydrogen electrode (RHE) at room temperature $\left(25^{\circ} \mathrm{C}\right)$ and atmospheric pressure, and high purity $\mathrm{H}_{2}$ (over $99.99 \%$ ) is directly generated without the need of separation.

\section{Results}

Elaboration of the EWGS process. In the EWGS process as illustrated in Fig. 1, CO is oxidized on the anode through Eq. (1) (the cations $\mathrm{K}^{+}$are omitted for clarity), where the product $\mathrm{CO}_{2}$ further reacts with hydroxide ion forming $\mathrm{CO}_{3}{ }^{2-}$ and thereby is transformed into a potassium carbonate $\left(\mathrm{K}_{2} \mathrm{CO}_{3}\right)$ avoiding the pollution caused by $\mathrm{CO}_{2}$ emission. Meanwhile, $\mathrm{H}_{2}$ is produced from $\mathrm{H}_{2} \mathrm{O}$ reduction on the cathode through Eq. (2):

$$
\begin{gathered}
\text { Anode : } \mathrm{CO}+4 \mathrm{OH}^{-} \rightarrow \mathrm{CO}_{3}^{2-}+2 \mathrm{H}_{2} \mathrm{O}+2 \mathrm{e}^{-} . \\
\text {Cathode }: 2 \mathrm{H}_{2} \mathrm{O}+2 \mathrm{e}^{-} \rightarrow \mathrm{H}_{2}+2 \mathrm{OH}^{-} \\
\text {Total }: \mathrm{CO}+2 \mathrm{OH}^{-} \rightarrow \mathrm{H}_{2}+\mathrm{CO}_{3}^{2-}
\end{gathered}
$$

Anion exchange membrane was employed for separating the cathode and anode, maintaining the balance of ion concentration of electrolyte, and hindering cross-contamination of the anodic $\left(\mathrm{CO}_{2}\right)$ and cathodic $\left(\mathrm{H}_{2}\right)$ reaction products in the system. Hence, the additional separation process as required in the traditional WGS reaction is precluded. In addition to $\mathrm{H}_{2}$ production, the other product $\mathrm{K}_{2} \mathrm{CO}_{3}$ in this EWGS is widely applied in the production of glass, soap, etc. in industry. The $\mathrm{K}_{2} \mathrm{CO}_{3}$ possesses higher added value than $\mathrm{KOH}$ because the production of $\mathrm{K}_{2} \mathrm{CO}_{3}$ in industry is from the reaction of $\mathrm{KOH}$ with $\mathrm{CO}_{2}$. Therefore, compared with the traditional WGS, the EWGS features a completely different catalytic reaction process and can operate at room temperature and ambient pressure, which opens a new avenue toward the direct production of high purity hydrogen with low-energy consumption.

Optimization of the anode structure. When operating the EWGS reaction in aqueous electrolyte, we identified two key factors that significantly affect the performance of $\mathrm{CO}$ oxidation. One is the diffusion of $\mathrm{CO}$ in the water phase due to its low solubility. Increasing the local concentration of $\mathrm{CO}$ near the anode catalyst surface plays a crucial role in enhancing the reaction rate of $\mathrm{CO}$ oxidation. The other is the optimization of

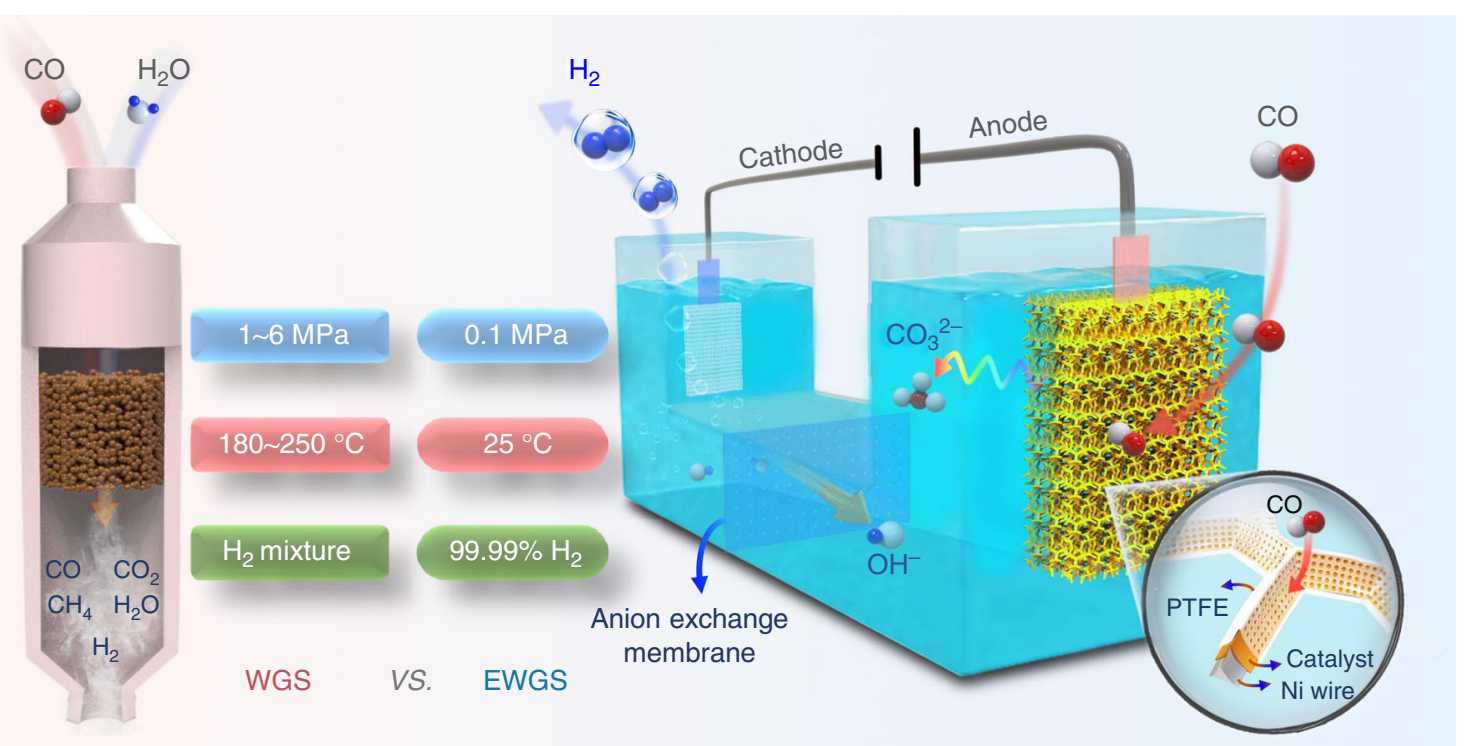

Fig. 1 Schematic diagram of the EWGS process compared with the traditional WGS process. The cations $\mathrm{K}^{+}$serve as the counter ions to balance the reaction 
the anode catalyst to exhibit high activity and durability, that could efficiently decrease the overpotential for the EWGS process. Hence, we will address the two key factors as follows by optimizing the structure of the anode and the catalyst to enhance the energy conversion efficiency of the EWGS process.

The diffusion of $\mathrm{CO}$ to the active sites which depends on two properties of the anode: (i) pore structure and surface area of the anode and (ii) the accessibility of surface sites to CO. For the first point, we adopted a conductive $\mathrm{Ni}$ foam with rich porous structure and high surface area as the anode support for loading catalysts to ensure sufficient exposure of catalyst to reactants (Fig. 1 and Supplementary Fig. 1). For the second point, we employed the traditional carbon supported platinum WGS catalyst $\mathrm{t}^{17,18}$ to optimize the anode structure. We deposited a hydrophobic polytetrafluoroethylene (PTFE) layer on commercial $\mathrm{Pt} / \mathrm{C}$ (40 wt\%) catalyst, aiming to build water-free compartments at the interface of PTFE and Pt to promote $\mathrm{CO}$ diffusion and facilitate CO colliding with the surface sites. Figure $2 \mathrm{a}$ and Supplementary Fig. 2a show that decoration of the catalyst with PTFE notably improves the $\mathrm{CO}$ oxidation activity and the anodic current density reaches the maximum at PTFE loading amount of $1.5 \mu \mathrm{g} \mathrm{cm}^{-2}$. Drop of current density at higher PTFE loading $\left(2.5 \mu \mathrm{g} \mathrm{cm}^{-2}\right)$ could be caused by the blocking of the active sites by the overloaded PTFE. Inspired by the feature of the hydrophobic PTFE layer, we supported Pt nanoparticles on well-graphitized carbon nanotubes (Pt@CNTs, 40 wt\%), which are pretreated in hydrogen at $400{ }^{\circ} \mathrm{C}$ to remove the oxygencontaining groups from the CNTs surface and improve hydrophobicity. The adsorption amount of $\mathrm{H}_{2} \mathrm{O}$ on the Pt@CNTs is much lower than that on the pristine $\mathrm{Pt} / \mathrm{C}$ and is further reduced upon PTFE treatment, as shown in the intelligent gravimetric analyzer tests (Fig. 2b). Linear sweep voltammetry polarization
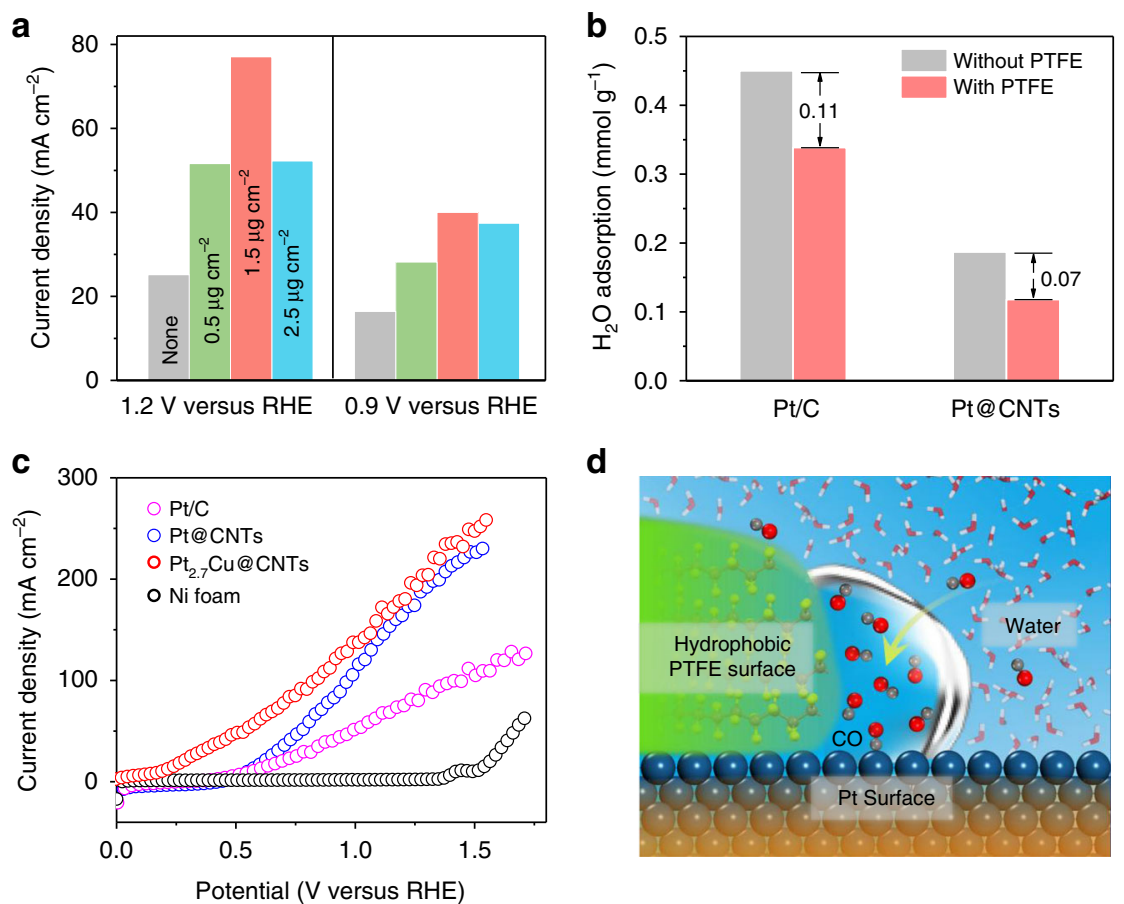

d
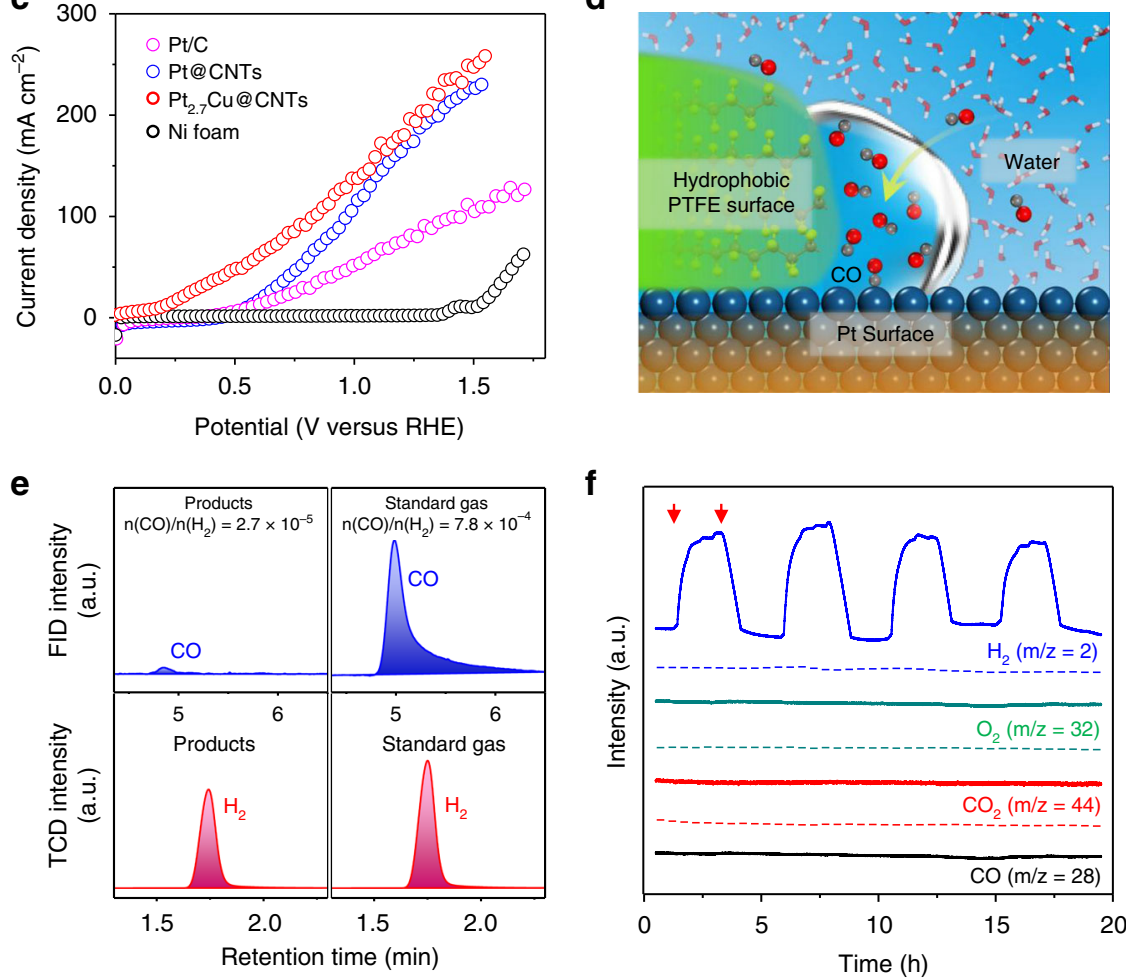

Fig. 2 Optimization of anode structure and performance of the EWGS process. a Current densities of CO oxidation on Pt/C catalyst decorated with different content of PTFE at 0.9 and $1.2 \mathrm{~V}$ versus RHE, respectively. $\mathbf{b}$ Adsorption of $\mathrm{H}_{2} \mathrm{O}$ at $25^{\circ} \mathrm{C}$ on Pt/C and Pt@CNTs with and without PTFE treatment detected by intelligent gravimetric analyzer. c Linear sweep voltammetry polarization curves of the CO oxidation catalyzed by Pt/C, Pt@CNTs, $\mathrm{Pt}_{2.7} \mathrm{Cu} @ \mathrm{CNTs}$, and Ni foam, all decorated with $1.5 \mu \mathrm{g} \mathrm{cm}-2$ PTFE. $\mathbf{d}$ Schematic illustration of solid/liquid/gas interfaces on the PTFE-decorated Pt surface. e Gas chromatography analysis of hydrogen purity for the cathodic products at a constant potential of 1.0 V versus RHE using Pt@CNTs as the anode catalyst, calibrated with the specific concentration of $\mathrm{CO} / \mathrm{H}_{2}$ standard gas. $\mathbf{f}$ Mass spectrometry detection of the anodic (dotted line) and cathodic (solid line) products using Pt@CNTs as the anode catalyst at a constant current density of $20.0 \mathrm{~mA} \mathrm{~cm}{ }^{-2}$. The red arrows denote starting and ending of CO inlet. All tests were carried out in $\mathrm{CO}$-saturated $1 \mathrm{M} \mathrm{KOH}$ solution at $25^{\circ} \mathrm{C}$ 
curves show that the current density of the Pt@CNTs anode catalyst reaches about twice that of the commercial $\mathrm{Pt} / \mathrm{C}$ at potentials over $0.75 \mathrm{~V}$ (Fig. $2 \mathrm{c}$ and Supplementary Fig. 2b), though the size of the Pt nanoparticles supported on the CNTs is slightly larger than that of the commercial Pt/C (Supplementary Fig. 3). These results indicate that the presence of PTFE and CNTs significantly improves the hydrophobicity of the catalyst, which facilitates the diffusion and adsorption of $\mathrm{CO}$ and improves the anodic reaction activity via creating solid/liquid/ gas interfaces (Fig. 2d).

During the activity measurements of the Pt@CNTs anode catalyst, the faradic efficiency for $\mathrm{H}_{2}$ production at the cathode maintains around $100 \%$ in a wide range of working potential and the $\mathrm{H}_{2}$ purity can reach over $99.99 \%$ (Fig. 2e and Supplementary Fig. 4). Only trace amounts (27 ppm) of $\mathrm{CO}$ are detected in the cathode output, which may be due to the microleakage from the anode side through the anion exchange membrane (Fig. 2e). In a cyclic process of open/close-circuit operation of the EWGS system, neither $\mathrm{CO}_{2}$ and $\mathrm{O}_{2}$ gases in the anode chamber nor $\mathrm{CO}$ gas in the cathode chamber is detected by mass spectrometry (Fig. $2 \mathrm{f}$ ). These results confirm the direct production of high-purity $\mathrm{H}_{2}$ without additional separation through the EWGS process.

Elucidation of the anodic reaction mechanism. Optimizing the activity of catalyst requires understanding of the structure and its relation to the catalytic reaction mechanism. Supported metal nanoparticles typically expose multiple crystallographic planes, which exhibit distinct catalytic activities. High-angle annular dark field scanning transmission electron microscopy (HAADFSTEM) images of the Pt@CNTs sample (Fig. 3a and Supplementary Figs. 5a, b) show that the Pt nanoparticles mainly expose the face-centered cubic (111), (200), and (220) surfaces, which is consistent with the X-ray diffraction analysis (Supplementary Fig. 6a). To clarify the activity of different crystal faces in CO oxidation, we conducted the cyclic voltammogram (CV) tests of the reaction using three single crystallographic $\mathrm{Pt}$ anodes (Fig. 3b), in which the $\mathrm{Pt}(111)$ surface gives the lowest onset potential of $0.44 \mathrm{~V}$ compared with that of $0.47 \mathrm{~V}$ on (100) and $0.50 \mathrm{~V}$ on $(110)$ surfaces.

To provide insights into the activity trend of different $\mathrm{Pt}$ facets, density functional theory (DFT) calculations were performed to study the underlying reaction mechanism. The adsorbed $\mathrm{CO}\left(\mathrm{CO}^{\star}\right)$ reacts either with $\mathrm{OH}^{-}$or $\mathrm{OH}^{\star}$ through associative mechanisms ${ }^{19,20}\left(\right.$ via $\left.\mathrm{COOH}^{\star}\right)$ or with $\mathrm{O}^{\star}$ through a redox mechanism ${ }^{12}$, leading to the formation of $\mathrm{CO}_{2}$ (see Fig. $3 \mathrm{c}$ and Supplementary Methods for detailed data). Among the three reaction channels, the direct attack of $\mathrm{CO}^{\star}$ by $\mathrm{OH}^{-}$in the solvent is most favored on all three Pt surfaces, as shown in the free energy diagrams in Fig. $3 \mathrm{~d}$ and Supplementary Fig. 7 (see Supplementary Fig. 8 and Supplementary Table 2 for detailed data). Formation of the $\mathrm{COOH}^{*}$ is the most endergonic electrochemical step and determines the overpotentials of the anode reaction, which follows the order of $0.99 \mathrm{~V}$ on $\operatorname{Pt}(110)>0.68 \mathrm{~V}$ on $\operatorname{Pt}(100)>0.55 \mathrm{~V}$ on $\mathrm{Pt}(111)$, in good accordance with the trend in experimental observations. Since the strength of $\mathrm{COOH}^{*}$ adsorption is less dependent on the surface structure than that of $\mathrm{CO}^{*}$ adsorption, as shown in Fig. 3e, the significant decrease in $\mathrm{CO}$ adsorption strength from $\mathrm{Pt}(110)$ to $\mathrm{Pt}(111)$ is primarily responsible for the enhanced activity on $\mathrm{Pt}(111)$. As the surface coordination number increases from $\mathrm{Pt}(110)$ to $\mathrm{Pt}(111)$, the $d$-band center shifts down from -2.21 to $-2.44 \mathrm{eV}$, leading to reduced backdonation of the $d$ electrons of Pt to the CO $2 \pi^{\star}$ states (Fig. $3 \mathrm{f}$ ). Consequently, the $\mathrm{CO}$ adsorption is weakened, which favors the electrochemical oxidation of CO.
Rational design of the anode catalyst. Our theoretical calculations demonstrate that the activity of CO oxidation in EWGS process increases with the weakened interaction between $\mathrm{CO}$ and anode catalyst surface. Alloying Pt with other metals has been proved as an effective strategy of modulating the surface activity. Rational selection of a suitable alloying component to destabilize $\mathrm{CO}$ adsorption on the catalyst surface is conducted following two strategies. First, the component itself should bind $\mathrm{CO}$ less strongly than $\mathrm{Pt}$, and thus the inert coinage metals such as $\mathrm{Cu}$, $\mathrm{Ag}$, and $\mathrm{Au}$ are chosen as potential components ${ }^{21-24}$, Second, the formation of alloy should shift the $d$-band center of surface $\mathrm{Pt}$ atoms down to a lower energy level. Considering that alloying $\mathrm{Pt}$ with $\mathrm{Au}$ and $\mathrm{Ag}$ will increase the lattice constant of $\mathrm{Pt}^{25}$ and shift the $d$-band center up ${ }^{26}, \mathrm{Cu}$ is finally chosen as the component to modulate the $\mathrm{CO}$ adsorption activity on the Pt surface. In addition, alloying with $\mathrm{Cu}$ will also reduce the $\mathrm{Pt}$ loading and hence the constituent cost for potential industrial applications. By constructing $\mathrm{Pt}_{3} \mathrm{Cu}$ model, we observed the decrease of lattice constant of $\mathrm{Pt}_{3} \mathrm{Cu}$ by $0.08 \AA$ compared with $\mathrm{Pt}$ and the increase of $d$-band width of $\mathrm{Pt}_{3} \mathrm{Cu}(111)$ with $d$-band center shifted down to $-2.47 \mathrm{eV}$, as shown in Fig. 3f. Consequently, $\mathrm{CO}$ adsorption on the $\mathrm{Pt}$ site of $\mathrm{Pt}_{3} \mathrm{Cu}(111)$ is weakened (Fig. 3e) and the overpotential of $\mathrm{CO}$ oxidation is lowered by $0.10 \mathrm{~V}$ compared with that of $\mathrm{Pt}(111)$ (Fig. 3d).

Electrochemical performance of PtCu@CNTs catalyst. Based on these theoretical insights, we prepared a series of PtCu@CNTs catalysts with $\mathrm{Pt} / \mathrm{Cu}$ mole ratio varying from 1.2 to 6.0 (Supplementary Figs. 5, 6, and Supplementary Table 1) and measured their activity toward CO oxidation using linear sweep voltammetry. These alloy samples all exhibit lower onset potentials than that of the Pt@CNTs in the polarization curves (Fig. 4a and Supplementary Fig. 2c). The $\mathrm{Pt}_{2.7} \mathrm{Cu} @ \mathrm{CNT}$ s anode catalyst shows the best performance with the lowest onset potential of almost $0 \mathrm{~V}$ versus RHE (Fig. 4a and Supplementary Fig. 2d), leading to significant increase of $\mathrm{H}_{2}$ production rate on the cathode of the EWGS process compared with the case of Pt@CNTs as the anode catalyst (Fig. 4b). At a moderate operating potential of $0.6 \mathrm{~V}$ versus RHE, the current density of $\mathrm{CO}$ oxidation on $\mathrm{Pt}_{2.7} \mathrm{Cu} @ \mathrm{CNTs}$ reaches $70.0 \mathrm{~mA} \mathrm{~cm}^{-2}$, which is more than 12 times that of the pristine $\mathrm{Pt} / \mathrm{C}$ catalyst without PTFE treatment (Supplementary Fig. 2c). This validates our strategies of optimizing the anode structure and catalyst in improving the anode activity. In contrast to the electrocatalytic water splitting ${ }^{27-32}$, the EWGS process provides a promising alternative route of hydrogen production with much lower working voltage. Moreover, the faradaic efficiencies of both electrode reactions ( $\mathrm{CO}$ oxidation to $\mathrm{CO}_{3}{ }^{2-}$ and $\mathrm{H}_{2}$ formation) are approximately $100 \%$ in a wide range of working potential (Fig. $4 \mathrm{~b}$ and Supplementary Fig. 9). The superior activity of the PtCu alloy catalysts is in good agreement with our theoretical predictions. X-ray absorption near edge spectroscopy (XANES) on the Pt L-edge shows a notable decrease in the white-line intensity for $\mathrm{Pt}_{2.7} \mathrm{Cu} @ \mathrm{CNT}$ s compared to the Pt@CNTs catalyst (Supplementary Fig. 6c), indicating a lower transition probability of electrons from the core level to the empty $5 d$ bands of Pt. This is attributed to the partial filling of the $5 d$ bands of $\mathrm{Pt}$ by the electrons transferred from $\mathrm{Cu}$, which reduces the amount of empty $5 d$ states and lower the $d$-band center of $\mathrm{Pt}$ atoms, and in turn weaken the $\mathrm{CO}$ adsorption on the Pt atoms as shown in the DFT calculations (Fig. 3e).

Investigation on the durability of $\mathrm{Pt}_{27} \mathrm{Cu} @ \mathrm{CNT}$ catalyst indicated that the device can be operated stably for more than $475 \mathrm{~h}$ at a constant potential of $0.6 \mathrm{~V}$ versus RHE (Fig. 4c). During the process, formation and accumulation of carbonate ions in the electrolyte from $\mathrm{CO}$ oxidation will affect the reaction equilibrium and impede the 
a
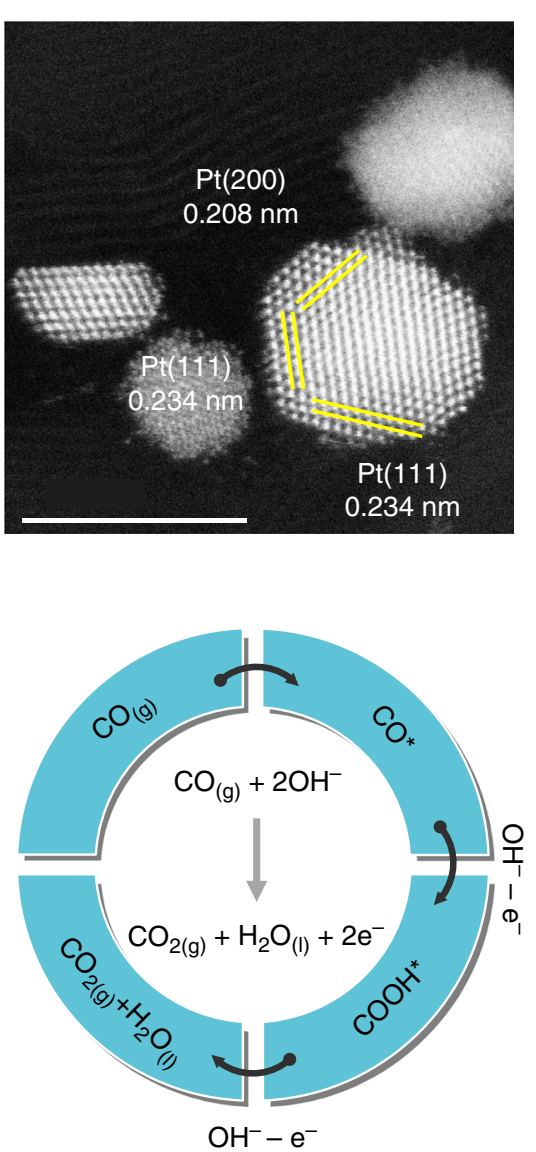

e

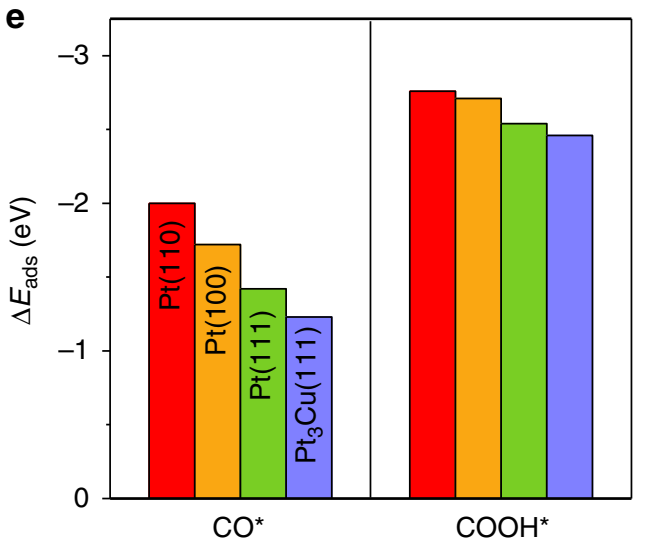

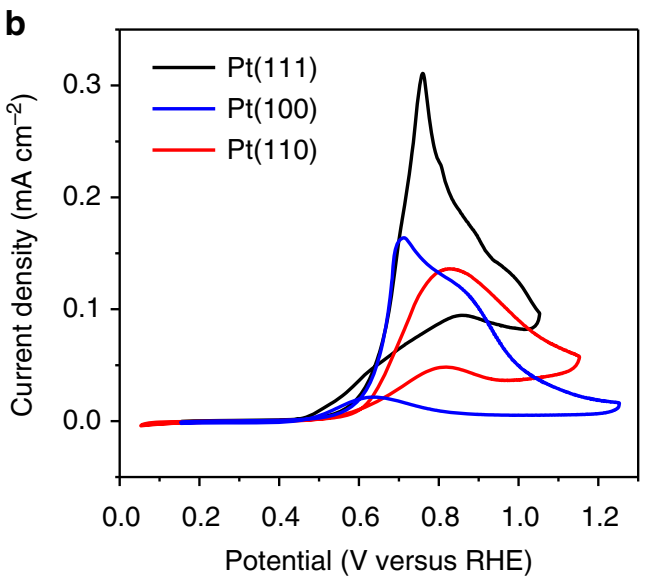

d

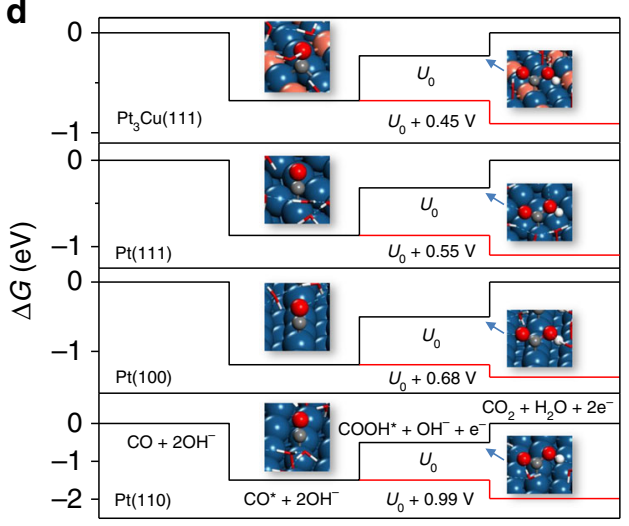

Reaction coordinate

f

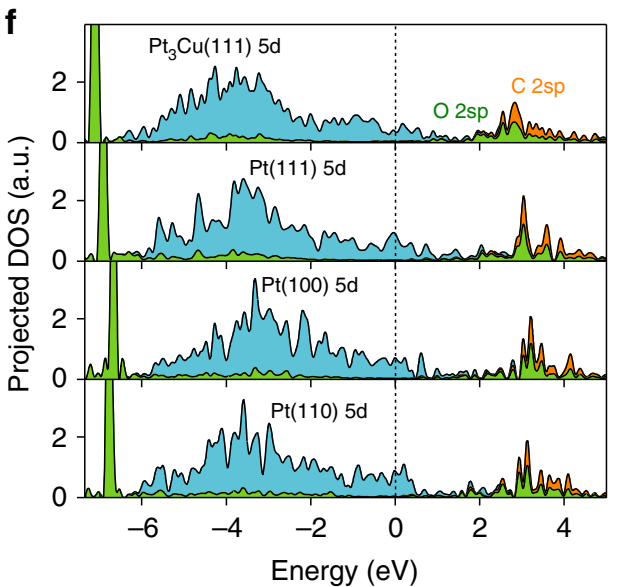

Fig. 3 Insights into the reaction mechanism of different Pt facets towards the EWGS. a HAADF-STEM image of Pt@CNTs, scale bar: 5 nm. b CV test of Pt (111), Pt(110), and Pt(100) electrodes in CO-saturated $0.01 \mathrm{M} \mathrm{KOH}$ at $25^{\circ} \mathrm{C}$ with a sweep rate of $50 \mathrm{mV} \mathrm{s}{ }^{-1}$. c Reaction path of the EWGS process in

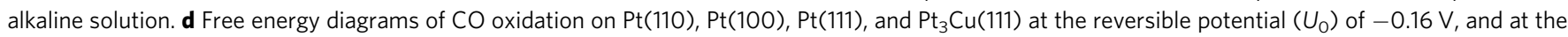
overpotentials that all reaction steps are downhill in free energy. e, $\mathbf{f}$ Comparison of the adsorption energies ( $\Delta E_{\text {ads }}$ ) of $\mathrm{CO}$ and $\mathrm{COOH}$ and projected density of states of $\mathrm{CO}$ on $\mathrm{Pt}(110), \mathrm{Pt}(100), \mathrm{Pt}(111)$, and $\mathrm{Pt}_{3} \mathrm{Cu}(111)$ in water environment

reaction kinetics (Supplementary Figs. 9 and 10). Thus, the electrolyte is replaced regularly to alleviate this effect and restore the activity. XANES characterization of the $\mathrm{Pt}_{2.7} \mathrm{Cu} @ \mathrm{CNT}$ s catalyst after $475 \mathrm{~h}$ of stability test shows that the valence states of the $\mathrm{Cu}$ and $\mathrm{Pt}$ components were almost the same as that of the original catalyst, and no obvious change of the $\mathrm{Cu}-\mathrm{Cu}$ bond and $\mathrm{Pt}-\mathrm{Pt}$ bond in extended X-ray absorption fine structure (EXAFS) was observed (Fig. 4d, e and Supplementary Fig. 6b, c), which demonstrates the high stability of $\mathrm{Pt}_{2.7} \mathrm{Cu} @ \mathrm{CNTs}$ as the anode catalyst of the EWGS process.

\section{Discussion}

In summary, we report a novel EWGS process for direct hydrogen production with over $99.99 \%$ purity and approximately $100 \%$ faradic efficiency under mild conditions. Combining experiments with theoretical calculations in the rational design of the anode structure and the catalyst composition to promote the $\mathrm{CO}$ oxidation reaction, the EWGS process can be driven with an anodic onset potential lowered to almost $0 \mathrm{~V}$ and an anodic current density of $70.0 \mathrm{~mA} \mathrm{~cm}^{-2}$ with long-term stability of over $475 \mathrm{~h}$ 

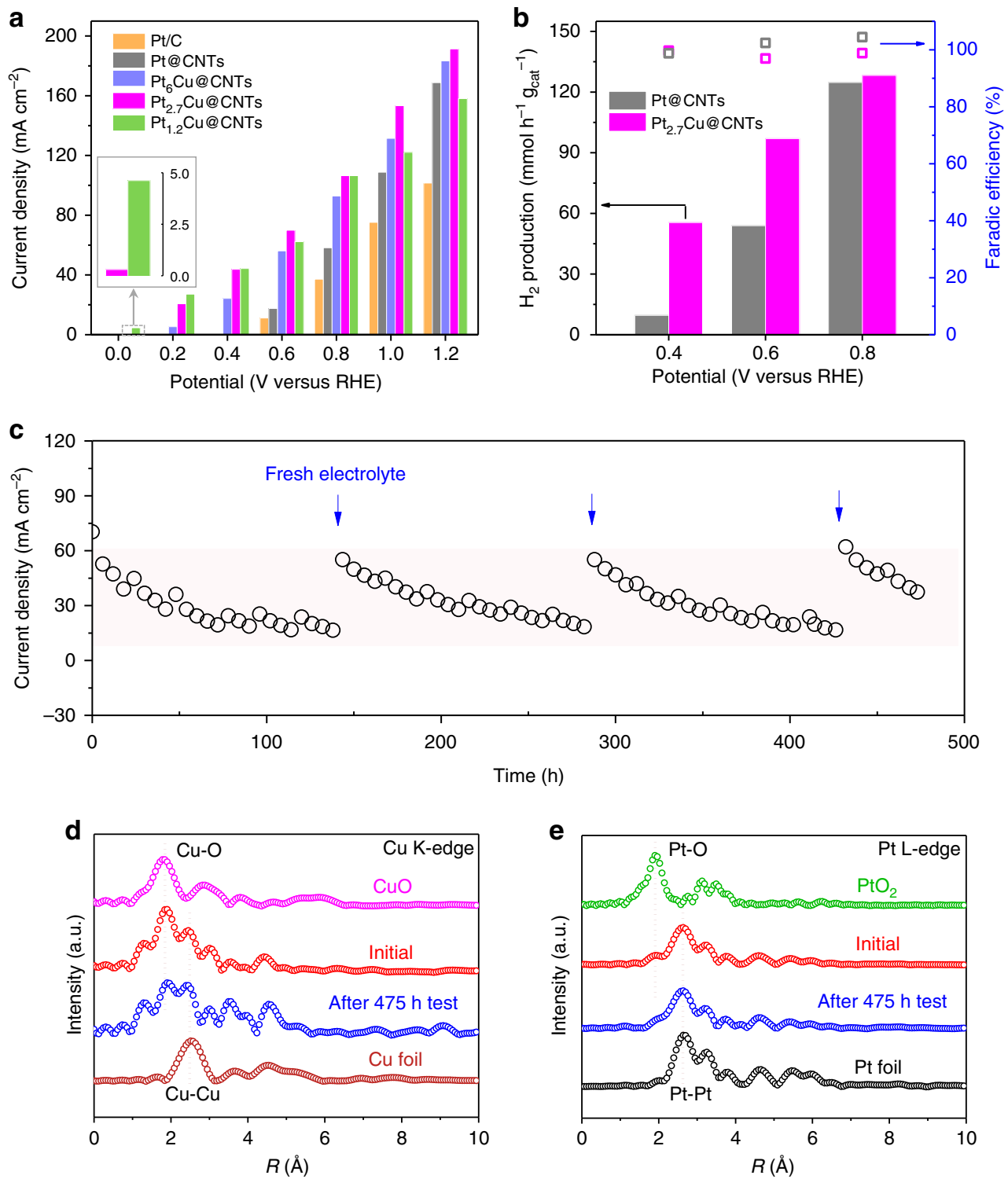

Fig. 4 Activity and stability of the PtCu@CNTs anode catalysts for the EWGS. a The current density of CO oxidation on the Pt/C, Pt@CNTs, and $\mathrm{PtCu} @ C N T s$ at different potentials. Inset shows that the current density at $0 \mathrm{~V}$ versus RHE reaches 0.2 and $4.6 \mathrm{~mA} \mathrm{~cm}^{-2}$ for Pt ${ }_{2.7} \mathrm{Cu} @ \mathrm{CNTs}$ and $\mathrm{Pt}_{1.2} \mathrm{Cu} @ \mathrm{CNTs}$, respectively. b The rate of $\mathrm{H}_{2}$ production and faradaic efficiency on the cathode at different potentials with the Pt ${ }_{2.7} \mathrm{Cu} @ \mathrm{CNTs}$ and Pt@CNTs as the anode catalysts. c Durability test of the Pt ${ }_{2.7} \mathrm{Cu} @ \mathrm{CNTs}$ at a constant potential of $0.6 \mathrm{~V}$ versus RHE. The blue arrows denote the time of replacing the electrolyte. The tests in a-c are performed in CO-saturated $1 \mathrm{M} \mathrm{KOH}$ solution at $25^{\circ} \mathrm{C}$. $\mathbf{d}$, e The $k^{2}$-weighted EXAFS spectra of the Cu K-edge (d) and Pt L-edge (e) of the $\mathrm{Pt}_{2.7} \mathrm{Cu} @ \mathrm{CNT}$ s sample before and after $475 \mathrm{~h}$ of stability test, compared with those of $\mathrm{Cu}$ foil, $\mathrm{CuO}$, $\mathrm{Pt}$ foil, and $\mathrm{PtO}{ }_{2}$, respectively

when operated at $0.6 \mathrm{~V}$ versus RHE. Considering the abundant $\mathrm{CO}$ feedstock, and the advantages of low-energy input and highenergy conversion efficiency in contrast to either traditional WGS reaction or the electrolysis of water, the EWGS process provides a new and promising platform to produce high purity hydrogen.

\section{Methods}

Preparation of catalysts. $\mathrm{H}_{2} \mathrm{PtCl}_{6} \cdot 6 \mathrm{H}_{2} \mathrm{O}, \mathrm{CuCl}_{2} \cdot 2 \mathrm{H}_{2} \mathrm{O}, \mathrm{KOH}$, and $\mathrm{CH}_{3} \mathrm{CH}_{2} \mathrm{OH}$ were purchased from Sinopharm chemical reagent Co., Ltd. Hydroxyfunctionalized multi-walled carbon nanotubes were purchased from Chengdu organic chemicals Co. Ltd. The commercial Pt/C (40 wt\%) was purchased from Johnson Matthey Corp. All chemicals were used as received without further purification.

For Pt@CNTs (40 wt\%) catalyst preparation, $70.0 \mathrm{mg}$ of hydroxy-functionalized multi-walled carbon nanotubes were firstly dispersed into the mixture of $30 \mathrm{~mL}$ ethanol and $10 \mathrm{~mL} \mathrm{H}_{2} \mathrm{O}$, and then ultrasonically treated for $30 \mathrm{~min}$. Subsequently, $0.239 \mathrm{mmol}$ of $\mathrm{H}_{2} \mathrm{PtCl}_{6} \cdot 6 \mathrm{H}_{2} \mathrm{O}$ solution was added drop by drop into the suspension. Afterwards, the mixture was stirred at room temperature until dry.
Then the sample was transferred into a chemical vapor deposition furnace and heated with temperature programmed from room temperature to $400{ }^{\circ} \mathrm{C}$ under $50 \% \mathrm{H}_{2} / \mathrm{Ar}$, and was kept at $400^{\circ} \mathrm{C}$ for $1 \mathrm{~h}$. After cooling down to room temperature, $2 \% \mathrm{O}_{2} / \mathrm{Ar}$ was led through to passivate the sample. The obtained catalyst was denoted as Pt@CNTs.

For preparation of the $\mathrm{PtCu} @ \mathrm{CNTs}$ catalysts, the $\mathrm{H}_{2} \mathrm{PtCl}_{6} \cdot 6 \mathrm{H}_{2} \mathrm{O}$ and $\mathrm{CuCl}_{2} \cdot 2 \mathrm{H}_{2} \mathrm{O}$ with different mole ratio were supported on the hydroxyfunctionalized multi-walled carbon nanotubes by an impregnation method as used in the Pt@CNTs preparation procedure. The difference is that the PtCu@CNTs precursors were reduced under $50 \% \mathrm{H}_{2} / \mathrm{Ar}$ at $250^{\circ} \mathrm{C}$. According to the mole ratio of $\mathrm{Pt}$ and $\mathrm{Cu}$, the catalysts were denoted as $\mathrm{Pt}_{1.2} \mathrm{Cu} @ \mathrm{CNTs}, \mathrm{Pt}_{2.7} \mathrm{Cu} @ \mathrm{CNT}$ s and $\mathrm{Pt}_{6} \mathrm{Cu} @ \mathrm{CNTs}$, respectively.

Evaluation of catalytic performance. Electrochemical measurements were performed on CHI 630, CHI 760, and PARSTAT MC (Princeton Applied Reasearch) with a three-electrode $\mathrm{H}$-type full electrochemical cell equipped with a gas flow controlling system. The anode and cathode compartments were divided by a quaternary ammonium polysulfone (chloride) anion exchange membrane (aQAPS$\mathrm{S}_{6}$ membrane: quaternary). The catalysts loaded on $\mathrm{Ni}$ foam, $\mathrm{Pt}$ net and $\mathrm{Hg} / \mathrm{HgO}$ 
were used as the working electrode, counter electrode and reference electrode, respectively. The Ni foam $(1 \mathrm{~cm} \times 1 \mathrm{~cm} \times 0.5 \mathrm{~cm})$ was washed by acetone, ethanol and deionized water thoroughly before use. Firstly, $9.0 \mathrm{mg}$ of catalyst was dispersed in the mixture of ethanol and deionized water with $10 \mu \mathrm{L}$ Nafion solution $(5 \mathrm{wt} \%$, $\mathrm{Du}$ Pont) to form homogeneous ink assisted by ultrasound. Then the ink was added dropwise onto the $\mathrm{Ni}$ foam and dried under the infrared lamp. After that, the PTFE solution (1 wt\%) was dropped on one side of Ni foam with different content as the hydrophobic layer and dried under the infrared lamp. During all the measurements, the Ni foam electrode was made as "L" type to enable part of the electrode exposed to $\mathrm{CO} / \mathrm{Ar}$ atmosphere, and $\mathrm{CO}$ or Ar was bubbled through the electrolyte solution of the anode and cathode with a flow rate of $50 \mathrm{~mL} \mathrm{~min}^{-1}$. Linear sweep voltammetry with a scan rate of $10 \mathrm{mV} \mathrm{s}^{-1}$ was measured in $1 \mathrm{M}$ $\mathrm{KOH}$ electrolyte. All the potentials have been referenced to the reversible hydrogen electrode (versus RHE). The durability test of $\mathrm{Pt}_{2.7} \mathrm{Cu} @ \mathrm{CNTs}$ was carried out by chronoamperometry at $0.6 \mathrm{~V}$ versus RHE in $1 \mathrm{M} \mathrm{KOH}$ electrolyte with CO flow rate of $50 \mathrm{~mL} \mathrm{~min}-1$, respectively. After every $24 \mathrm{~h}$, CO flow was switched to $\mathrm{Ar}$ for about $10 \mathrm{~min}$ and then back to CO again. The electrolyte is replaced every $144 \mathrm{~h}$ to eliminate the negative effect of the produced carbonate on the $\mathrm{CO}$ oxidation reaction equilibrium.

The single crystallographic $\operatorname{Pt}(111), \operatorname{Pt}(100)$, and $\operatorname{Pt}(110)$ electrodes (with a $2 \mathrm{~mm}$ diameter) were annealed by $\mathrm{CH}_{4}$ flame and cooled in $\mathrm{Ar}$ and $\mathrm{H}_{2}$ mixture (3:1) gas atmosphere prior to each experiment. After cooling down, every electrode was quickly transferred to a clean electrochemical cell under the protection of a drop of ultrapure water. After bubbling the electrolyte with $\mathrm{CO}$ for a certain time, cyclic voltammetry experiments were carried out in the CO-saturated $0.01 \mathrm{M} \mathrm{KOH}$ aqueous solution on the static electrode without rotation at $25^{\circ} \mathrm{C}$.

Gas chromatography analysis. The amount of hydrogen and carbon monoxide were quantified by the gas chromatograph (Shimadzu GC 2014) with a thermal conductivity detector (TCD) and a flame ionization detector (FID) coupled with a methanizer. Two identical MS-13X columns were connected to TCD and FID with argon and nitrogen used as the carrier gas, respectively. The faradaic efficiency (FE) of hydrogen from the cathode products was calculated by the following Eq. (4):

$$
\mathrm{FE}\left(\mathrm{H}_{2}\right)=\frac{Q_{\mathrm{H}_{2}}}{Q_{\text {total }}}=\frac{\text { Peak area }}{\left(\mathrm{H}_{2}\right)} \times v \times t \times \frac{2 F P_{0}}{R T} \times \frac{1}{Q_{\text {total }}},
$$

where $\alpha$ is a conversion factor based on calibration of the gas chromatograph with a series of standard sample, $v$ is the gas flow rate, $t$ is the reaction time, and $F$ is the Faraday's constant $96,485 \mathrm{C} \mathrm{mol}^{-1} . P_{0}=101.325 \mathrm{kPa}, R=8.314 \mathrm{~J} \mathrm{~mol}^{-1} \mathrm{~K}^{-1}$, and $T=298.15 \mathrm{~K} . Q_{\text {total }}$ is the total number of charges transferred in the circuit.

DFT calculations. Spin-polarized DFT calculations were performed with the Vienna Ab-initio Simulation Package (VASP) ${ }^{33}$. The interaction between the ionic cores and electrons was described by the projector-augmented wave method, and the Kohn-Sham valence electronic wavefunction was expanded in a plane-wave basis set with a kinetic energy cutoff at $400 \mathrm{eV}$. The exchange-correlation effects were represented within the generalized gradient approximation using the Perdew-Burke-Ernzerhof (PBE) exchange-correlation functional ${ }^{34}$. The energies were converged to within $10^{-4} \mathrm{eV}$ atom ${ }^{-1}$, and the forces were converged to within $0.03 \mathrm{eV}^{-1}$.

\section{Data availability}

The data that support the plots within this paper and other findings of this study are available from the corresponding author upon reasonable request.

Received: 31 July 2018 Accepted: 16 November 2018

Published online: 08 January 2019

\section{References}

1. Schlapbach, L. \& Zuttel, A. Hydrogen-storage materials for mobile applications. Nature 414, 353-358 (2001).

2. Burch, R. Gold catalysts for pure hydrogen production in the water-gas shift reaction: activity, structure and reaction mechanism. Phys. Chem. Chem. Phys. 8, 5483-5500 (2006).

3. Rhodes, C., Hutchings, G. J. \& Ward, A. M. Water-gas shift reaction-finding the mechanistic boundary. Catal. Today 23, 43-58 (1995).

4. Rodriguez, J. A. et al. The activation of gold and the water-gas shift reaction: Insights from studies with model catalysts. Acc. Chem. Res 47, 773-782 (2014).

5. Schoedel, A., Ji, Z. \& Yaghi, O. M. The role of metal-organic frameworks in a carbon-neutral energy cycle. Nat. Energy 1, 16034 (2016).

6. Kim, W. B., Voitl, T., Rodriguez-Rivera, G. J. \& Dumesic, J. A. Powering fuel cells with $\mathrm{CO}$ via aqueous polyoxometalates and gold catalysts. Science 305 , $1280-1283$ (2004).
7. Choi, Y. \& Stenger, H. G. Water gas shift reaction kinetics and reactor modeling for fuel cell grade hydrogen. J. Power Sources 124, 432-439 (2003).

8. Holladay, J. D., Hu, J., King, D. L. \& Wang, Y. An overview of hydrogen production technologies. Catal. Today 139, 244-260 (2009).

9. Zhai, Y. P. et al. Alkali-stabilized Pt-OHx species catalyze low-temperature water-gas shift reactions. Science 329, 1633-1636 (2010).

10. Ratnasamy, C. \& Wagner, J. P. Water gas shift catalysis. Catal. Rev. 51, 325-440 (2009).

11. Wang, T. F., Porosoff, M. D. \& Chen, J. G. G. Effects of oxide supports on the water-gas shift reaction over Pt-Ni bimetallic catalysts: Activity and methanation inhibition. Catal. Today 233, 61-69 (2014).

12. Gokhale, A. A., Dumesic, J. A. \& Mavrikakis, M. On the mechanism of lowtemperature water gas shift reaction on copper. J. Am. Chem. Soc. 130, $1402-1414$ (2008).

13. Fu, Q. et al. Interface-confined ferrous centers for catalytic oxidation. Science 328, 1141-1144 (2010).

14. Venkataraman, R., Kunz, H. R. \& Fenton, J. M. CO-tolerant, sulfided platinum catalysts for PEMFCs. J. Electrochem. Soc. 151, 710-715 (2004).

15. Oettel, C., Rihko-Struckmann, L. \& Sundmacher, K. Combined generation and separation of hydrogen in an electrochemical water gas shift reactor (EWGSR). Int. J. Hydrog. Energy 37, 6635-6645 (2012).

16. Oettel, C., Rihko-Struckmann, L. \& Sundmacher, K. Characterisation of the electrochemical water gas shift reactor (EWGSR) operated with hydrogen and carbon monoxide rich feed gas. Int. J. Hydrog. Energy 37, 11759-11771 (2012).

17. Ding, K. et al. Identification of active sites in $\mathrm{CO}$ oxidation and water-gas shift over supported Pt catalysts. Science 350, 189-192 (2015).

18. Buitrago, R. et al. Water gas shift reaction on carbon-supported Pt catalysts promoted by $\mathrm{CeO}_{2}$. Catal. Today 180, 19-24 (2012).

19. Meunier, F. et al. Quantitative analysis of the reactivity of formate species seen by DRIFTS over a $\mathrm{Au} / \mathrm{Ce}(\mathrm{La}) \mathrm{O}_{2}$ water-gas shift catalyst: First unambiguous evidence of the minority role of formates as reaction intermediates. J. Catal. 247, 277-287 (2007).

20. Kalamaras, C. M., Americanou, S. \& Efstathiou, A. M. "Redox" vs. "associative formate with -OH group regeneration" WGS reaction mechanism on Pt/ $\mathrm{CeO}_{2}$ : effect of platinum particle size. J. Catal. 279, 287-300 (2011).

21. Kandoi, S. et al. Why $\mathrm{Au}$ and $\mathrm{Cu}$ are more selective than $\mathrm{Pt}$ for preferential oxidation of $\mathrm{CO}$ at low temperature. Catal. Lett. 93, 93-100 (2004).

22. Rodriguez, J. A. et al. Water gas shift reaction on $\mathrm{Cu}$ and $\mathrm{Au}$ nanoparticles supported on $\mathrm{CeO}_{2}(111)$ and $\mathrm{ZnO}(0001)$ : intrinsic activity and importance of support interactions. Angew. Chem. Int. Ed. 46, 1329-1332 (2007).

23. Liu, P. Water-gas shift reaction on oxide/ $\mathrm{Cu}(111)$ : rational catalyst screening from density functional theory. J. Chem. Phys. 133, 204705 (2010).

24. Knudsen, J. et al. A Cu/Pt near-surface alloy for water-gas shift catalysis. J. Am. Chem. Soc. 129, 6485-6490 (2007).

25. Ma, Y. \& Balbuena, P. B. Pt surface segregation in bimetallic $\mathrm{Pt}_{3} \mathrm{M}$ alloys: a density functional theory study. Surf. Sci. 602, 107-113 (2008).

26. Hammer, B. \& Nørskov, J. K. Theoretical surface science and catalysiscalculations and concepts. Adv. Catal. 45, 71-129 (2000).

27. Cui, X. J. et al. Single layer graphene encapsulating non-precious metals as high-performance electrocatalysts for water oxidation. Energy Environ. Sci. 9, 123-129 (2016).

28. Grimaud, A. et al. Activating lattice oxygen redox reactions in metal oxides to catalyse oxygen evolution. Nat. Chem. 9, 457-465 (2017).

29. Kumar, A. et al. Measuring oxygen reduction/evolution reactions on the nanoscale. Nat. Chem. 3, 707-713 (2011).

30. Nellist, M. R. et al. Potential-sensing electrochemical atomic force microscopy for in operando analysis of water-splitting catalysts and interfaces. Nat. Energy 3, 46-52 (2017).

31. Zhao, S. L. et al. Ultrathin metal-organic framework nanosheets for electrocatalytic oxygen evolution. Nat. Energy 1, 1-10 (2016).

32. Ng, J. W. D. et al. Gold-supported cerium-doped $\mathrm{NiO} x$ catalysts for water oxidation. Nat. Energy 1, 16053 (2016).

33. Kresse, G. \& Furthmuller, J. Efficient iterative schemes for ab initio totalenergy calculations using a plane-wave basis set. Phys. Rev. B 54, 11169-11186 (1996).

34. Perdew, J. P., Burke, K. \& Ernzerhof, M. Generalized gradient approximation made simple. Phys. Rev. Lett. 77, 3865-3868 (1996).

\section{Acknowledgments}

We gratefully acknowledge the financial support from the Ministry of Science and Technology of China (Nos. 2016YFA0204100, 2017YFA0204800, and 2016YFA0200200), the National Natural Science Foundation of China (Nos. 21890753, 21573220 and 
21621063), the Key Research Program of Frontier Sciences of the Chinese Academy of Sciences (No. QYZDB-SSW-JSC020), the DNL Cooperation Fund, CAS (No. DNL180201), and National Postdoctoral Program for Innovative Talents (BX201700140). We thank the staff at the BL14W1 beamline of the Shanghai Synchrotron Radiation Facilities for assistance with the EXAFS and XANES measurements. We also thank Ke Gong for the assistance in NMR tests.

\section{Author contributions}

D.D. conceived the study. X.C. and R.C. performed the materials synthesis, characterization, and performance test. H-Y.S. and L.Y. contributed to the DFT calculations. J.D. and J.L. performed the CV test of single crystallographic Pt electrodes. C.M. and S.W. performed the electron microscopy study. D.M., F.Y., J.X., and M.Z. assisted partial experiments and manuscript revision. X.B., Z.T., and D.Z. provided constructive suggestions. X.C., H-Y.S., R.C., L.Y., and D.D. wrote the paper.

\section{Additional information}

Supplementary Information accompanies this paper at https://doi.org/10.1038/s41467018-07937-w.

Competing interests: The authors declare no competing interests.
Reprints and permission information is available online at http://npg.nature.com/ reprintsandpermissions/

Publisher's note: Springer Nature remains neutral with regard to jurisdictional claims in published maps and institutional affiliations.

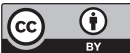

Open Access This article is licensed under a Creative Commons Attribution 4.0 International License, which permits use, sharing, adaptation, distribution and reproduction in any medium or format, as long as you give appropriate credit to the original author(s) and the source, provide a link to the Creative Commons license, and indicate if changes were made. The images or other third party material in this article are included in the article's Creative Commons license, unless indicated otherwise in a credit line to the material. If material is not included in the article's Creative Commons license and your intended use is not permitted by statutory regulation or exceeds the permitted use, you will need to obtain permission directly from the copyright holder. To view a copy of this license, visit http://creativecommons.org/ licenses/by/4.0/.

(C) The Author(s) 2019 